\title{
POST COITAL VAGINAL TEAR - A RARE LIFE THREATENING EMERGENCY
}

Manohar R1, Kavyashree G²

\section{HOW TO CITE THIS ARTICLE:}

Manohar R, Kavyashree G. "Post coital vaginal tear - a rare life threatening emergency". Journal of Evolution of Medical and Dental Sciences 2013; Vol2, Issue 40, October 07; Page: 7637-7639.

ABSTRACT: Post coital vaginal tear or rupture is a well known entity to the gynecologist .Coitusinduced vaginal tear in a parous woman with no prior pelvic surgery or other risk factors is a rare clinical presentation. Here we present a case of Post coital vaginal tear which presented as a life threatening emergency.

INTRODUCTION: Non obstetric vaginal lacerations differ greatly from lacerations sustained during childbirth and are generally classified into two types. The first type is relatively minor and is associated with normal sexual intercourse. These lacerations usually resolve with minimal treatment. The second type of laceration is deeper and more extensive, often resulting in significant vaginal bleeding. This condition can be life threatening and requires immediate intervention

CASE PRESENTATION: Mrs. XX, 30 years old lady, P2L2, presented with the complaints of excessive bleeding per vagina since 4 hours to emergency OBG ward at night. She gives h/o passage of clots and had changed about 3 to 4 clothes which was fully soaked .Her previous menstrual cycles were regular 3-4 days/30 days LMP: day 1. She had both FTND at government hospital, P1-male 9 years, p2-female 6 years. She had undergone laparoscopic sterilization 6 year back.

On General physical examination - she was moderately built and nourished and severely anaemic. Her Pulse rate was $120 \mathrm{bpm}$, feeble, low volume, and BP- systolic was $80 \mathrm{~mm} \mathrm{Hg}$, Her tongue was dry, extremities were cold, and tachypnea -20/min was present.

Per Abdomen Examination was soft and non tender, and there was no organomegaly.

Per Speculum examination revealed an Annular tear about $4 \mathrm{~cm}$ present at the cervicovaginal junction posterolaterally on the right side.

On Bimanual examination Uterus was anteverted, normal in size, firm, mobile, fornices free and non tender.
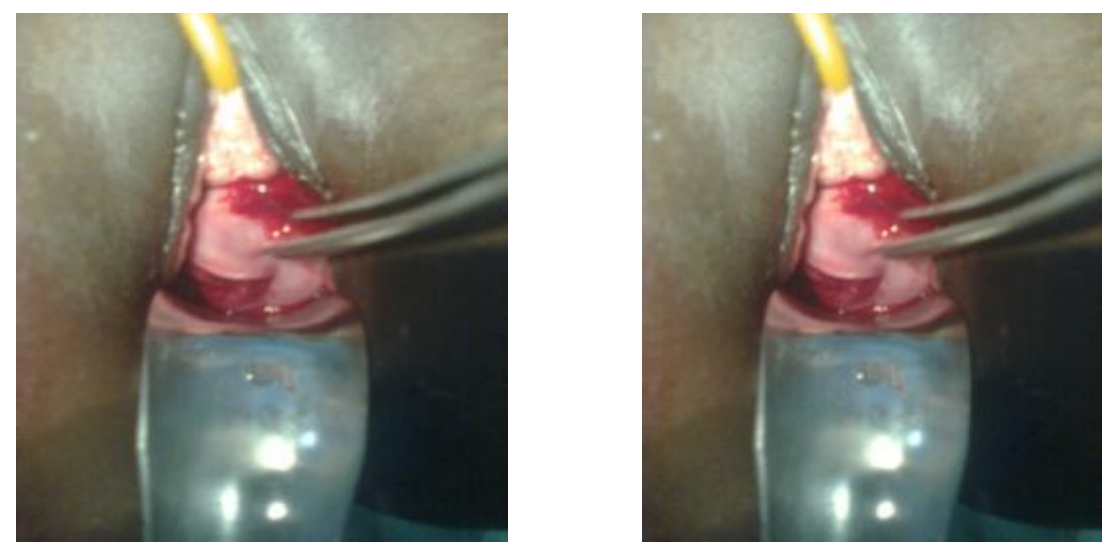

Annular tear at cervico-vaginal junction postero-laterally:

Journal of Evolution of Medical and Dental Sciences/ Volume 2/ Issue 40/ October 07, 2013 


\section{CASE REPORT}

A detailed history was then taken, and she gave history of coitus, followed by excessive bleeding since 4 hours.

TREATMENT: Immediate resuscitation was done by Foot end elevation, 18 G IV cannula was inserted and blood was collected for grouping/Rh typing/cross matching. Bladder catheterization was done initially - 2 pint Normal Saline and 1 pint Haemaccel was transfused. Her Hb\% was $6 \mathrm{gm} / \mathrm{dl}$ and she was transfused with 1 pint of blood. After resuscitating the patient, under IV sedation, vaginal tear was sutured intermittently using chromic catgut no 0 and haemostasis secured. Inj Taxim 1gm IV was given. She was later transfused with 2 pints of blood on day 2 and 3 after admission. IV antibiotics were continued for 3 days and patient was discharged on 5th day with hematinics and analgesics. Patient came for follow up on 14 th day.

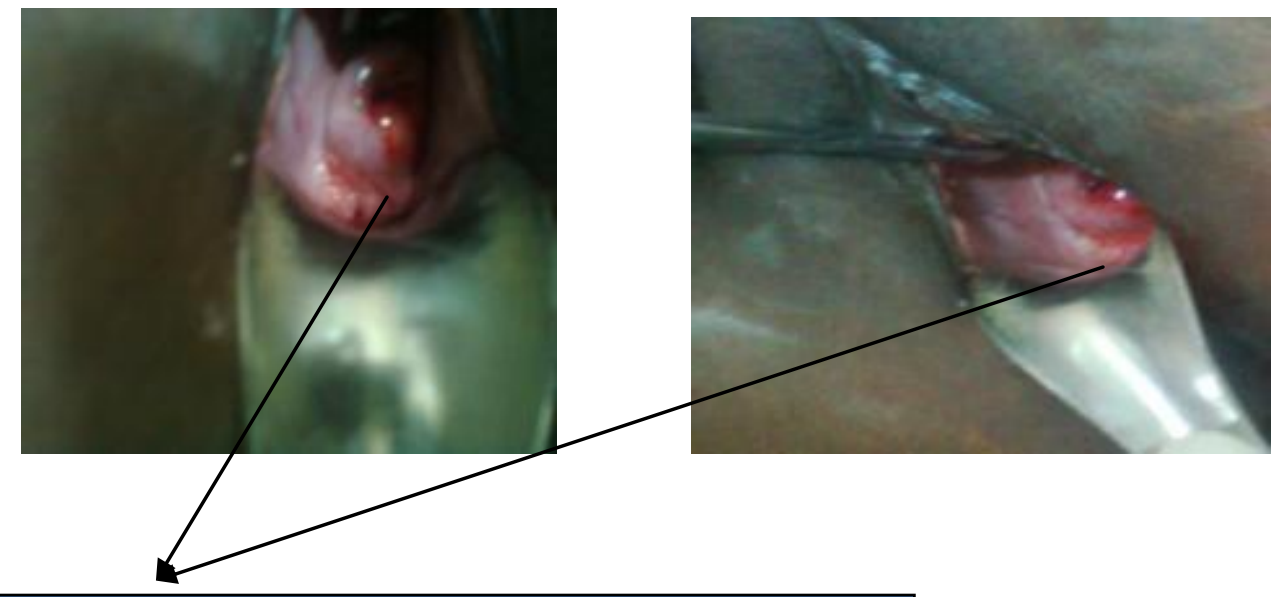

Healed scar at the cervico-vaginal junction on $14^{\text {th }}$ day.

DISCUSSION: Vaginal lacerations may be single or multiple. It has been reported that the vaginal tears are located most frequently in the posterior and lateral walls and in the vault of the vagina, often in the right rather than the left lateral wall. Geist reported that up to $75 \%$ of women in the emergency department with vaginal lacerations require repair. Hemorrhagic shock may be present in $15 \%$ of cases. The lacerations tend to be $3-5 \mathrm{~cm}$ long and usually located in the posterior vagina. They are more commonly located posteriorly and to the right. Lacerations extending into the peritoneal cavity occur in less than $1 \%$ of patients. Hall et al, and Tabriskey et al, reported a case of vaginal vault laceration per se with evisceration of the bowel during coitus, approximately two months after an uncomplicated vaginal hysterectomy.

Predisposing and etiological factors that can account for such injuries include virginity, disproportion of male and female genitalia, and atrophic vagina in post -menopausal women, friability of tissues, stenosis and scarring of the vagina because of congenital abnormalities, previous surgeries or pelvic radiation therapy. Other factors include rough and vigorous thrusting of the penis during intercourse, insertion of foreign bodies and sexual assault. Coital positioning, especially in cases of dorsal decubitus, with hyperflexion and of the thighs and sitting position have also been suggested ads pre-disposing factors.

The right fornix is usually longer than the left and is therefore more likely to be stretched by it, and hence less likely to sustain injury. 
In this case the post coital vaginal tear was present in parous women without any risk factors and situated right posterolaterally at the cervico-vaginal junction as explained in the above studies.

CONCLUSION: Due to embarrassing situations, fear and social stigma it is very possible that some women will offer incomplete histories of the events, leading to trauma to the vulva or vagina due to vigorous sexual activity. In such situations, the gynecologist has to make appropriate presumptions, and be prepared to treat the injury, despite an apparently negative or even misleading history. Post coital vaginal tear can rarely present as a life threatening emergency and should be kept in mind as a differential diagnosis by a gynecologist when a patient presents with bleeding per vagina.

\section{REFERENCES:}

1. Austin JM, Cooksey CM, Minikel LL, and Zaritsky EF. Postcoital vaginal rupture in a young woman with no prior pelvic surgery. J Sex Med 2013; 10:2121-2124.

2. Boraih S, Sheela SR and Shetty MVK: Post Coital Fourth Degree Rectovaginal perineal Tear: A Rare Case Report. Int J Pharm Sci Res. 3(11); 4372-4373.

3. Geist BE Sexually Related Trauma, Emergency Medicine Clinics of North America 1988;6:439-466

4. Marvin M. Sloin, DO: Pedram lbeigi, DO, Non obstetric Lacerations Of the Vagina, Journal of the American Osteopathic Association 271-273.

5. R. Narkunam, S. Raman, A. Kulenthran, T.A. Sinnathuray, Coital Injuries: A Study of Three Cases, med. j. Malaysia Vol. 39 78-81.

\section{AUTHORS:}

1. Manohar R.

2. Kavyashree G.

\section{PARTICULARS OF CONTRIBUTORS:}

1. Assistant Professor, Department of Obstetrics and Gynaecology, Mandya Institute of Medical Sciences, Mandya.

2. Associate Professor, Department of Obstetrics and Gynaecology, Mandya Institute of Medical Sciences, Mandya.

\author{
NAME ADDRESS EMAIL ID OF THE \\ CORRESPONDING AUTHOR: \\ Dr. Manohar, \\ No. 2977, $8^{\text {th }}$ Cross, \\ Ashok Nagar, Mandya - 571401. \\ Email- manoharrangaswamy@gmail.com \\ Date of Submission: 23/09/2013. \\ Date of Peer Review: 24/09/2013. \\ Date of Acceptance: 27/09/2013. \\ Date of Publishing: 01/10/2013.
}

